Developmental Biology

\title{
ATRX has a critical and conserved role in mammalian sexual differentiation
}

Huyhn et al. 


\title{
ATRX has a critical and conserved role in mammalian sexual differentiation
}

\author{
Kim Huyhn², Marilyn B Renfree ${ }^{1,2}$, Jennifer A Graves ${ }^{2,3}$ and Andrew J Pask $k^{1,4^{*}}$
}

\begin{abstract}
Background: X-linked alpha thalassemia, mental retardation syndrome in humans is a rare recessive disorder caused by mutations in the ATRX gene. The disease is characterised by severe mental retardation, mild alphathalassemia, microcephaly, short stature, facial, skeletal, genital and gonadal abnormalities.

Results: We examined the expression of ATRX and ATRY during early development and gonadogenesis in two distantly related mammals: the tammar wallaby (a marsupial) and the mouse (a eutherian). This is the first examination of ATRX and ATRY in the developing mammalian gonad and fetus. ATRX and ATRY were strongly expressed in the developing male and female gonad respectively, of both species. In testes, ATRY expression was detected in the Sertoli cells, germ cells and some interstitial cells. In the developing ovaries, ATRX was initially restricted to the germ cells, but was present in the granulosa cells of mature ovaries from the primary follicle stage onwards and in the corpus luteum. ATRX mRNA expression was also examined outside the gonad in both mouse and tammar wallaby whole embryos. ATRX was detected in the developing limbs, craniofacial elements, neural tissues, tail and phallus. These sites correspond with developmental deficiencies displayed by ATR-X patients.

Conclusions: There is a complex expression pattern throughout development in both mammals, consistent with many of the observed ATR-X syndrome phenotypes in humans. The distribution of ATRX mRNA and protein in the gonads was highly conserved between the tammar and the mouse. The expression profile within the germ cells and somatic cells strikingly overlaps with that of DMRT1, suggesting a possible link between these two genes in gonadal development. Taken together, these data suggest that ATRX has a critical and conserved role in normal development of the testis and ovary in both the somatic and germ cells, and that its broad roles in early mammalian development and gonadal function have remained unchanged for over 148 million years of mammalian evolution.
\end{abstract}

Keywords: Marsupial, eutherian, tammar wallaby, testis, ovary, germ cells

\section{Background}

The ATRX gene is located on the mammalian X-chromosome and is a member of the SNF-2-like helicase superfamily subgroup that contains genes involved in DNA recombination, repair and regulation of transcription [1]. Mutations in this gene cause ATR-X syndrome in humans, a sex-linked condition characterized by alpha thalassaemia, severe psychomotor retardation, characteristic facial features, microcephaly, short stature, cardiac, skeletal and urogenital abnormalities [2,3]. Urogenital abnormalities occur in $80 \%$ of patients and range

\footnotetext{
* Correspondence: andrew.pask@uconn.edu

${ }^{1}$ ARC Centre of Excellence for Kangaroo Genomics, Australia

Full list of author information is available at the end of the article
}

from complete male to female sex reversal [4], commonly associated with truncations of the C-terminus of the protein, to mild hypospadias [3]. However, the precise role of ATRX in gonadal development in mammals remains unclear. Although XY ATR-X patients have varying degrees of gonadal dysgenesis, a common feature is an absence of Müllerian ducts and differing degrees of virilization [5] showing that there is initial testis formation that subsequently becomes dysgenetic. The initial development of the testes indicates that the phenotype is not caused by sex reversal, but rather by early testicular failure and a subsequent lack of androgen. The absence of Müllerian ducts in affected individuals confirms the initial development of testes with functional Sertoli cells that are able to produce AMH
C Biomed Central

() 2011 Huyhn et al; licensee BioMed Central Ltd. This is an Open Access article distributed under the terms of the Creative Commons Attribution License (http://creativecommons.org/licenses/by/2.0), which permits unrestricted use, distribution, and reproduction in any medium, provided the original work is properly cited. 
(required for regression of the Müllerian ducts). Thus ATRX acts downstream of the sex-determining gene, $S R Y$ and of SOX9 that is required for Sertoli cell development and upregulation of $A M H$ in testicular development [6]. This is consistent with the analysis of testes from ATR-X patients with more mild gonadal phenotypes. Such testes typically show reduced numbers of seminiferous tubules and functional Leydig cells but an absence of germ cells $[4,7-9]$. Together these phenotypes suggest that there is an early failure to maintain a viable testis causing reduced virilization. Depending on how early in development testicular failure occurs, the developmental effects can range from severe to mild feminization [10].

The mouse X-linked ATRX gene shares $85 \%$ homology with its human orthologue [11]. However, marsupials are unique in that they have orthologues of $A T R X$ on both the $\mathrm{X}(A T R X)$ and $\mathrm{Y}(A T R Y)$ chromosomes. ATRX shares $72 \%$ and $78 \%$ sequence identity with mouse and human respectively [12], while ATRY shares 61\% sequence identity and $88 \%$ amino acid similarity with human and mouse ATRX [13]. The more divergent $A T R Y$ gene is functionally specialized, and is exclusively expressed in the male urogenital system, whereas ATRX has a broad pattern of mRNA expression in marsupials, as in mice and humans [6]. The only site where $A T R X$ and $A T R Y$ are co-expressed in the marsupial is in the adult testis [6]. ATRX is present in the somatic and germ cells of the adult testes of humans and rats, indicating a possible role in spermatogenesis [14].

Orthologues of ATRX have also been identified in the nematode Caenorhabditis elegans (C.elegans), suggesting it is an ancient and ultra-conserved gene in the sex determination cascade. The C.elegans ATRX orthologue (xnp1) has a remarkable conservation of function in gonadogenesis with human ATRX. xnp1 and lin35 (the orthologue to mammalian retinoblastoma) act in concert to regulate target gene expression in C.elegans. Their roles appear to be redundant since knockout of either $x n p 1$ or lin35 alone does not produce a phenotype. However, the double mutant has abnormalities, which, despite their divergence from humans, paralleled those seen in XY ATR-X patients. The mutants were sterile with severe defects in gonadal development and a decrease in germ cell numbers [15]. Many of the male C.elegans also exhibited defects in the structure and/or function of the male mating apparatus [15]. These abnormalities are analogous to the gonadal dysgenesis and external genitalia defects of XY ATR-X patients [5]. The mutant C.elegans also had other consistent characteristics with human ATR-X patients including patterning abnormalities and growth restriction $[5,15,16]$. There were also gonadal anomalies in female C.elegans double mutants, suggesting a potential role in ovarian development.
To date there are very few reports detailing ATRX expression in mammals, and none that examine its role in the early gonad. Marsupials provide a unique system to examine the function of this gene particularly in reference to gonadal development since there are two orthologues, ATRX on the X-chromosome, and ATRY on the Y-chromosome. To further define the role of this gene in early gonadal development in mammals we examined expression of both ATRX and ATRY in the developing marsupial gonad and of ATRX in the developing mouse gonad.

\section{Results}

The ATRX antibody used in this study (rabbit antihuman, Santa Cruz biotechnology, ATRX-H-300) binds with high affinity to both ATRX and ATRY in marsupials and as such cannot differentiate between the two orthologues. However, since only ATRY (and not ATRX) is expressed in the developing testes of marsupials [6], in situ and immunohistochemistry data in developing tammar wallaby testes demonstrates ATRY mRNA/protein distribution. Conversely, since ATRY is absent in XX females, all data in developing tammar ovaries represents ATRX mRNA/protein distribution. Similarly in mice, in which there is no Y-linked ATRY orthologue, all expression data represents ATRX mRNA/protein distribution. The only tissue in which ATRX/ATRY expression cannot be distinguished is in the adult tammar testis where the two genes are coexpressed [6]. A summary of ATRX and ATRY expression in the gonads of eutherian and marsupial mammals is shown in Table 1.

\section{ATRX and ATRY mRNA distribution in the developing mammalian testis}

Ubiquitous expression of $A T R X$ in mice and $A T R Y$ in marsupials was detected in the indifferent $X Y$ gonad before sexual differentiation by whole mount in situ hybridization. Staining was weak and diffuse, and localized throughout the entire gonad and mesonephros.

During testicular differentiation, ATRX mRNA distribution in the mouse was identical to ATRY mRNA distribution in the tammar testes at all stages examined (Figure $1 \mathrm{~A}, \mathrm{~B}, \mathrm{C}, \mathrm{D})$. We investigated the mouse from E11 through to E16.5 and equivalent development stages in the tammar wallaby testis from d24 of the 26.5 day gestation to day 40 post partum. The pattern of expression throughout these stages did not change from those shown in Figure 1. As development proceeded, ATRX/Y staining was lost in the mesonephros but persisted in the gonads. Intense staining was detected within the newly formed seminiferous cords (Figure 1C, D), suggesting localization of $A T R X / Y$ transcripts in the germ cells and Sertoli cells of the testis throughout its 
Table 1 Summary of ATRX and ATRY expression in the gonads of eutherian and marsupial mammals

\begin{tabular}{cccc}
\hline Tissue & Atrx Mouse & ATRX Tammar & ATRY Tammar \\
\hline Bi potential XY gonad & Yes & No & Yes \\
& Germ and somatic cells & Germ and somatic cells \\
\hline Developing Testis & Yes & No & Yes \\
& Sertoli, germ and Leydig cells & Sertoli, germ and \\
\hline Adult Testis & Yes $~$ & Yeydig and germ cells & Leydig and germ cells \\
\hline \hline Bi potential XX gonad & Yes & Absent \\
\hline Developing Ovary & Germ and somatic cells & Ges and somatic cells & Absent \\
\hline Adult Ovary & Germ cells & Yes & Germ cells \\
\hline
\end{tabular}

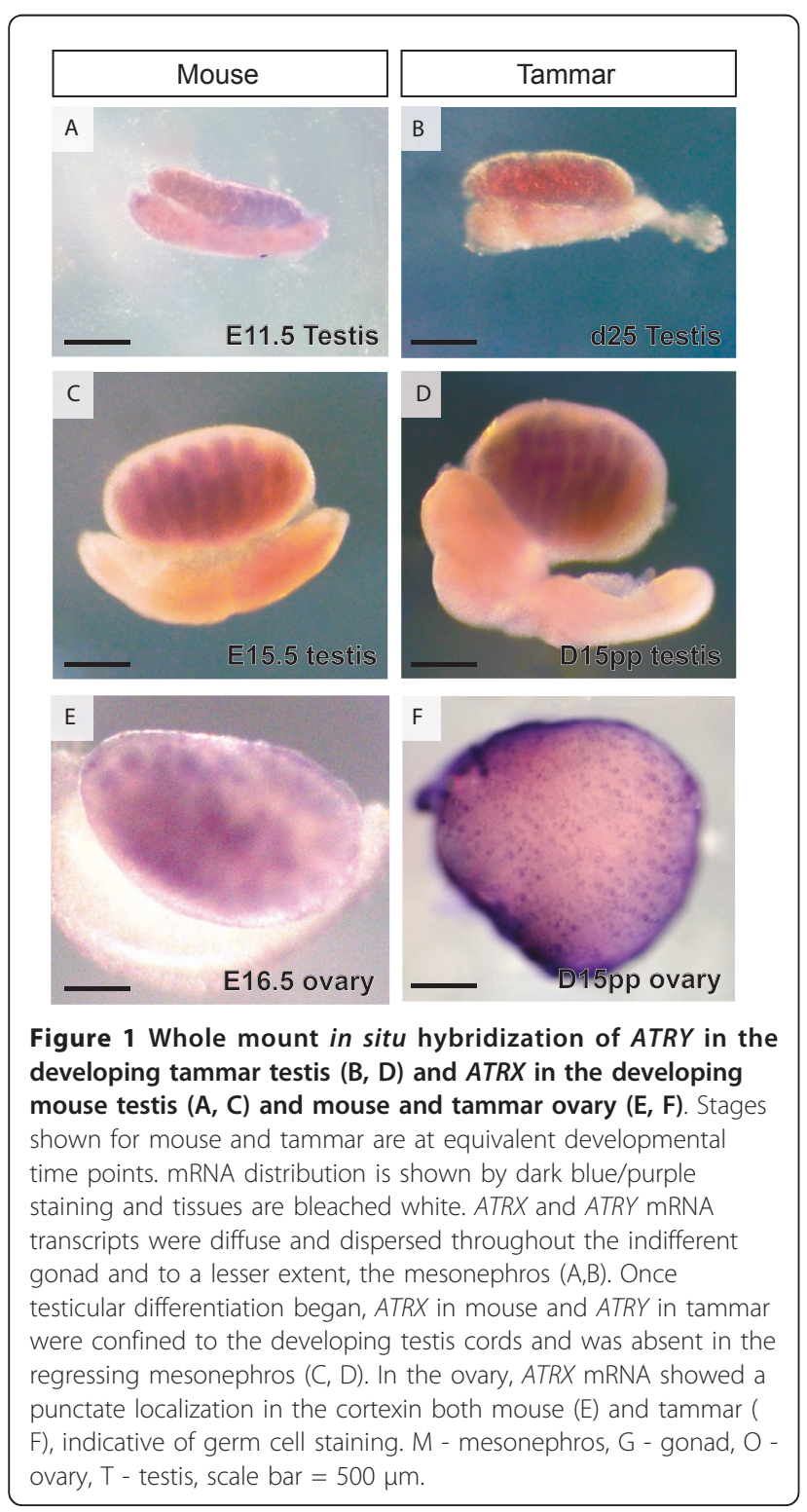

development. Diffuse staining was also seen in the interstitial tissue suggesting expression outside the cords.

\section{ATRX and ATRY protein distribution in the developing mammalian testis}

ATRY protein was detected by the ATRX antibody in both the nucleus and the cytoplasm of the somatic and germ cells of the developing male tammar, at the time of gonadal sex determination (Figure 2A). By day 2 post partum, the cords are defined and ATRY had become nuclear and was restricted to the Sertoli and germ cells (Figure 2C). This expression pattern persisted throughout development with additional ATRY protein found in a subset of the interstitial cells (including cells with a Leydig like shape and location) in later stage gonads (Figure 2E,G). An identical staining pattern was observed for ATRX protein in the mouse testis at E14.5 (Figure $2 \mathrm{H}$ ).

\section{ATRX and ATRY distribution in the adult tammar testis} Since ATRX and ATRY are co-expressed in the adult tammar testis [6], their differential protein localization was not able to be determined. ATRX/Y protein was present in the primary spermatogonia located at the base of the seminiferous tubules in the adult tammar testis (Figure 3A), but was lost from the mature Sertoli cell nuclei (Figure 3C). ATRX/Y protein was also detected in the interstitial cells (including cells with a Leydig like shape and location) and some - but not all peritubular myoid cells (Figure 3E).

\section{ATRX mRNA distribution in the developing mammalian ovary}

As in the testis, expression of ATRX and its protein localization in the developing ovary was identical between mice and marsupials. We investigated mouse stages from E11 through to E16.5 and equivalent stages 


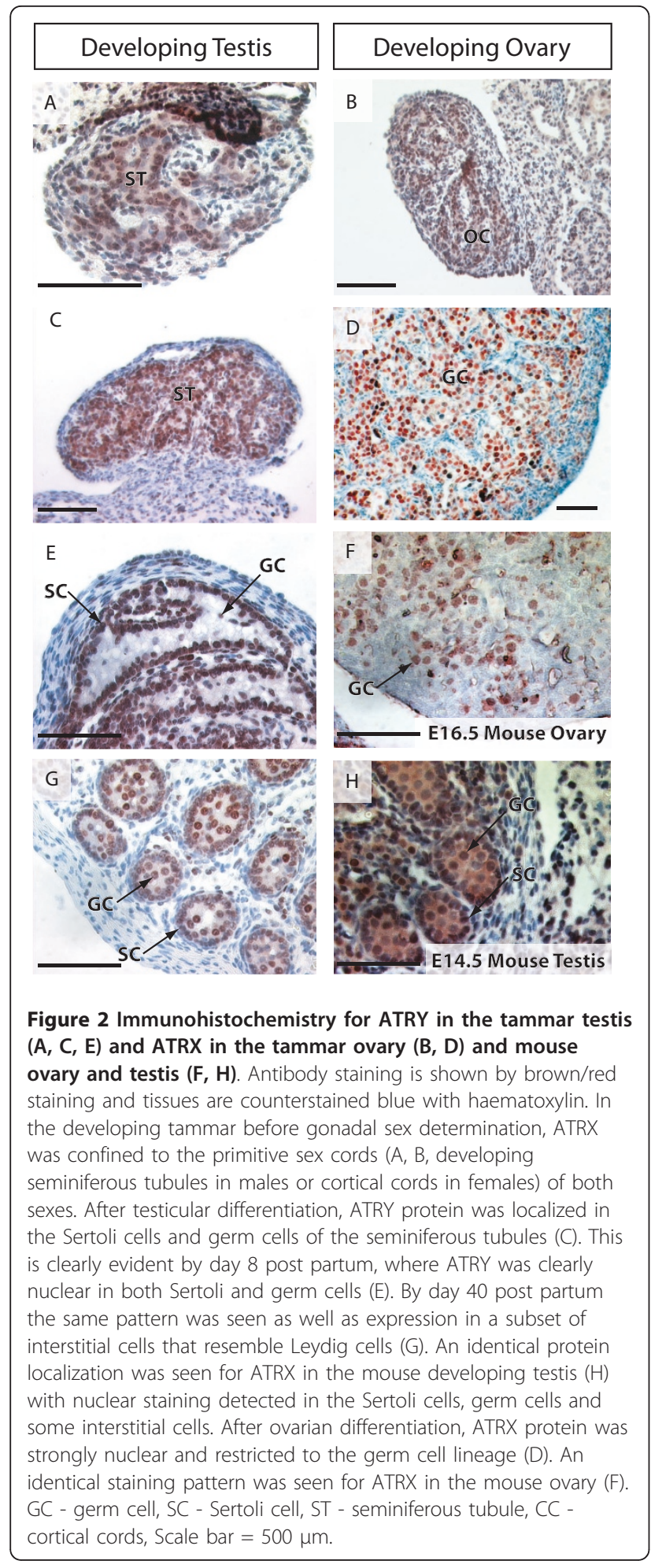

in the tammar wallaby (from $\mathrm{d} 24$ of gestation to day 40 post partum). The pattern of expression in these stages did not change from those shown in Figure 1. A weak staining pattern was identified throughout the gonad at early developmental time points. After sexual
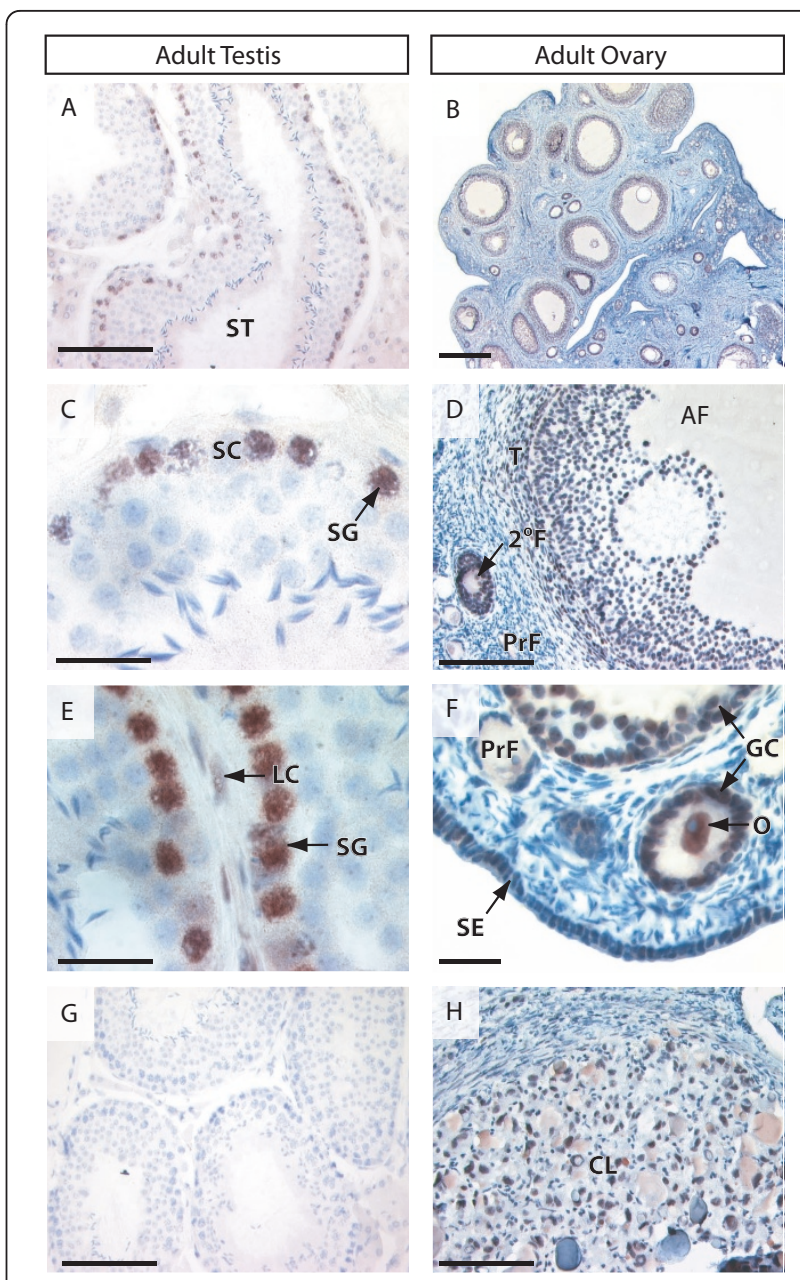

Figure 3 Immunohistochemistry of combined ATRX and ATRY in the adult tammar wallaby testis, and for ATRX in the adult tammar ovary. Antibody staining is shown by brown/red staining and tissues are counterstained blue with haematoxylin. In the adult testis, ATRX/Y was predominantly localized at the periphery of the seminiferous tubules (A). ATRX was nuclear in the primary spermatogonia but was absent from the Sertoli cells (C). Protein was also detected in the interstitial cells that resemble Leydig cells (E). In the adult ovary ATRX was seen in the granulosa cells of developing follicles (B) at all stages of growth, but not in primordial follicles (D, F). ATRX was also detected in the steroidogenic theca cells (D) of antral follicles, in the corpus luteum $(H)$, in the ovarian surface epithelium (F) and in the oocytes themselves (F). There was no staining in the antibody negative control (G). SG - spermatogonia, GC - germ cell, SC - Sertoli cell, LC - Leydig cell, ST - seminiferous tubule, AF - antral follicle, $T$ - theca, $2^{\circ} \mathrm{F}$ - secondary follicle, PrF primordial follicle, GC - granulosa cell, O - oocyte, SE - ovarian surface epithelium, Scale bars; A,D,G,H $=200 \mu \mathrm{m}, \mathrm{B}=500 \mu \mathrm{m}, \mathrm{C}, \mathrm{E}$, $\mathrm{F}=50 \mu \mathrm{m}$

differentiation, staining became more intense and punctate, indicative of protein within the germ cell nests (Figure $1 \mathrm{E}, \mathrm{F}$ ). A low level of diffuse staining also persisted throughout the somatic cells of the ovary but this was at a much lower level than that observed in the 
germ cells (Figure $1 \mathrm{E}, \mathrm{F}$ ). Thus the germ cells appear to be the major site of expression in the developing ovary. Again staining was observed in the mesonephros at early developmental time points (before gonadal sex determination) but was lost during gonadal development.

\section{ATRX protein distribution in the developing mammalian ovary}

Staining in the indifferent ovary was both cytoplasmic and nuclear, and identical to the staining observed in the indifferent testis (Figure 2A), restricted largely to the germ cells and some somatic cells (Figure 2B). As the ovary developed, ATRX antibody strongly stained in the nucleus of XX germ cells and was completely absent from the somatic cell lineages (Figure 2D). An identical staining pattern was seen in the E16.5 mouse ovary, with ATRX protein exclusively localized to the nuclei of germ cells (Figure 2F).

\section{ATRX distribution in the adult ovary}

ATRX protein persisted in the nuclei of developing oocytes but was also found at high levels in the nuclei of granulosa cells of growing follicles (Figure 3B, D). ATRX was not seen in the flattened granulosa cells of primordial follicles, but was abundant and nuclear in the cuboidal granulosa cells of follicles recruited to the growing pool (Figure 3F). ATRX was also detected in the luteal cells of the corpus luteum (Figure $3 \mathrm{H}$ ) and the theca cells of large antral follicles (Figure 3D). In addition ATRX was nuclear and abundant in the ovarian surface epithelium (Figure 3F).

\section{ATRX mRNA distribution in the developing mammalian embryo}

$A T R X$ mRNA distribution was identical and highly conserved in the mouse and tammar by whole mount in situ hybridization during early embryonic development. ATRX mRNA expression was pronounced in the developing fore- and hind-limbs, tail, craniofacial regions and developing brain. Staining in the craniofacial regions was consistently more intense in the anterior aspects where the nose and mouth are situated (Figure 4A, B). $A T R X$ mRNA was also seen in the neural tube and dorsal root ganglia at all stages. ATRX expression persisted in all tissues described above through E13.5 in the mouse. In the tammar at day 25 of gestation (one day before birth) staining was prominent in the hind limb (equivalent in stage to an E13.5 mouse hind limb) but was fading in the forelimb, which is developmentally accelerated and equivalent to an E17.5 mouse forelimb (Figure 4C, D, E, F, G, H). ATRX expression was also prevalent in the developing phallus of both mice and marsupials (Figure 4E; Figure 5A, B, C, D). ATRX expression is concentrated at the ventral midline (urethral grove) and in the preputial swellings of the mouse phallus (Figure 5A, B). This staining pattern was present at each stage examined from E10.5 to E16.5 in mouse and day 22 to day 25 of gestation to in the tammar. Immunohistochemistry of the developing phallus showed ATRX protein was present in the surface epithelium, sporadically in the mesenchyme and intensely stained the epithelium of the forming male urethra up until at least day 8 post partum.

\section{Discussion}

This is the first analysis of ATRX expression in the developing mammalian fetus, and demonstrates that the regional distribution of $A T R X$ mRNA is highly conserved between eutherian and marsupial mammals. All sites of expression correspond with developmental deficiencies found in ATR-X patients [2,6] (Table 1). There was strong expression of $A T R X$ in the developing brain, neural tube and dorsal root ganglia. These sites of expression are consistent with the psychomotor retardation, central nervous system and neural tube defects including spina bifida, scoliosis and kyphosis seen in ATR-X patients [2]. This suggests $A T R X$ plays a highly conserved and fundamental role not only in the brain but in multiple parts of the developing central nervous system in all mammals. The expression in the dorsal root ganglia suggests $A T R X$ may be essential for normal afferent nerve development and is consistent with hypotonia and some of the facial and limb muscle phenotypes observed in ATR-X patients.

$A T R X$ expression was very strong in the developing fore- and hind-limbs of the mouse and tammar. This was especially pronounced in early limb bud stages in the hand and footplate, suggesting a function in limb patterning. Hand abnormalities are frequently observed in ATR-X patients including clinodactyly, brachydactyly, tapering of the fingers, drum stick phalanges, cutaneous syndactyly and overlapping of the digits [2]. Foot deformities are also observed including pes planus, talipes equinovarus and talipes calcaneovalgus [2]. Together with our expression data, these phenotypes suggest $A T R X$ is essential in hand and footplate patterning in all mammals and that the phenotypes observed in ATR-X patients result from a combination of skeletal defects as well as hypotonia.

Many of the same patterning factors seen in the developing limb are also essential for phallus outgrowth and development [17]. ATRX fits into this class of factors as it was detected at high levels in the developing phallus. ATR-X patients frequently have penile abnormalities ranging from mild hypospadias and deficient prepuce to micropenis and severe hypospadias with ambiguous genitalia. The primary cause of these defects has been 

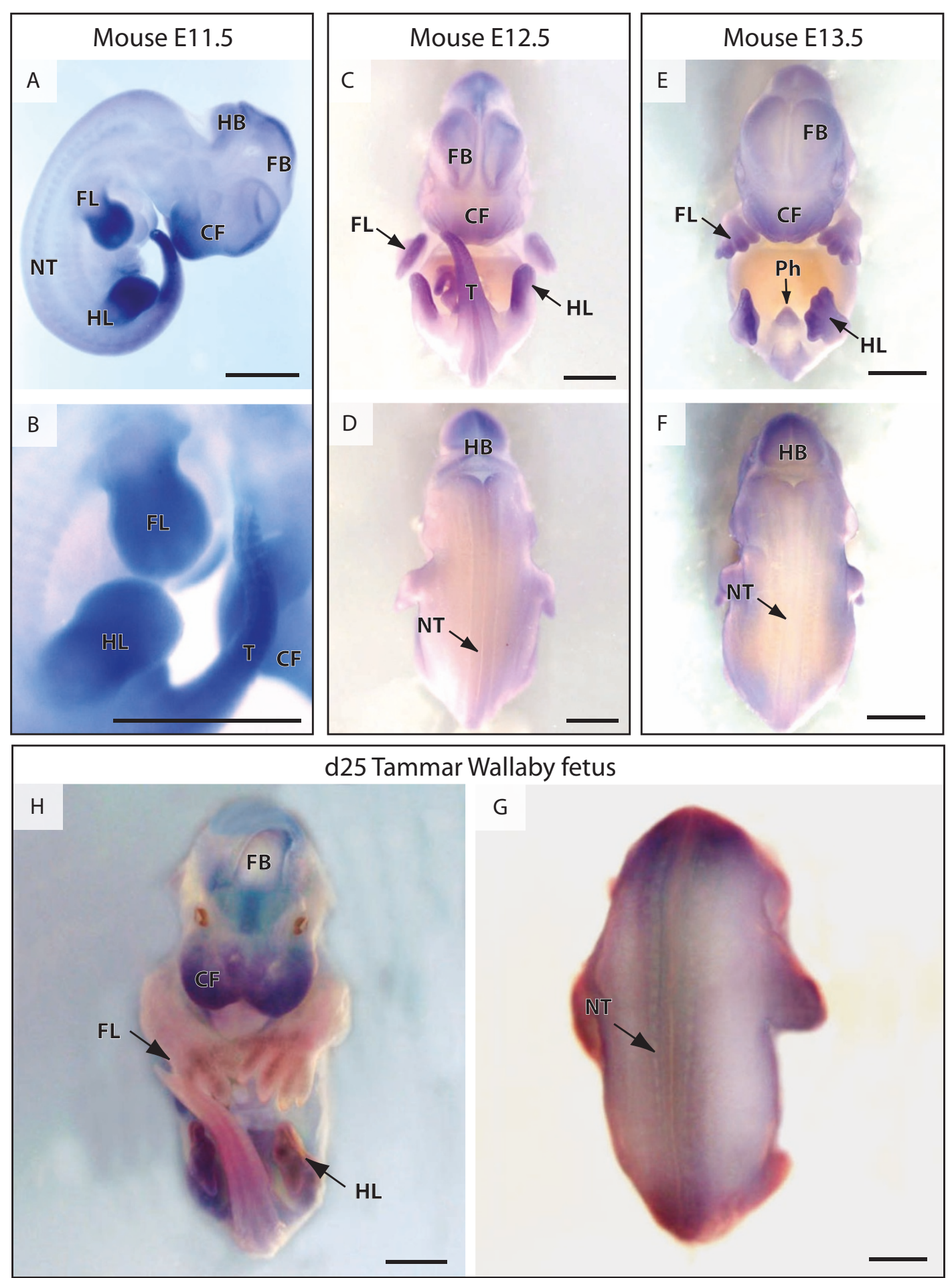

Figure 4 Whole mount in situ hybridization of $A T R X$ in the developing mouse and marsupial embryo. mRNA distribution is shown by dark blue/purple staining, while tissues are bleached white. In the E11.5 mouse, mRNA was concentrated in the developing limbs, tail and craniofacial regions of the fetus. Staining was also evident in the brain, neural tube and dorsal root ganglia (A, B). mRNA persisted in each of these domains throughout mouse development and was distinct in the forming hand and foot plate, developing phallus, fore and hind brain, dorsal root ganglia, neural tube and craniofacial regions (C-F). Identical zones of mRNA expression were detected in the near-term tammar wallaby fetus $(\mathrm{G}, \mathrm{H})$. HL - hind limb, FL - fore limb, P- phallus, FB - fore brain, HB - hind brain, NT - neural tube, CF - craniofacial regions, $T$ - tail. Scale bar $=2 \mathrm{~mm}$. 


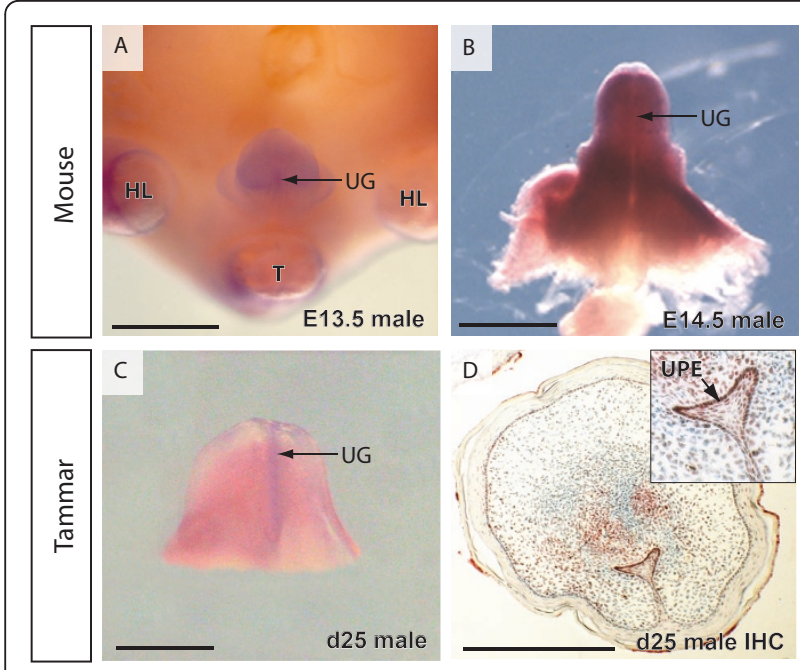

Figure 5 Expression and protein distribution of ATRX in the phallus. ATRX mRNA was seen throughout the developing genital tubercle in the male mouse (A, B). Hind limbs and tail were removed to allow clear observation of the phallus (A) or the entire phallus was removed $(B, C)$. mRNA appeared to be more concentrated in the urethral groove on the ventral side of the phallus $(A, B)$. Identical mRNA distribution was seen in the developing tammar phallus (C) again concentrated in the urethral groove. ATRX protein was distributed through cells of the tammar phallus mesenchyme but was concentrated in the urethral plate epithelium, lining the urethral groove (D) and enlarged insert (D) HL - hind limb, T - tail, UG - urethral groove, UPE - urethral plate epithelium. Scale bars; A,B $=1 \mathrm{~mm}$ and $C, D=500 \mu \mathrm{m}$.

attributed to gonadal dysgenesis. However, the dynamic expression of ATRX in the developing phallus with mRNA and protein concentrated in the developing urethral plate (a signaling center for phallus patterning and urethral closure) suggests that at least a subset of these defects may be due to a direct role of ATRX in penile development and not simply a lack of androgen. Similarly, undescended testes, common in ATR-X patients, could also be the direct result of deficient genitofemoral nerve function or development [18], consistent with the expression detected in the dorsal root ganglia of developing embryos and may not necessarily be a secondary effect of androgen deficiency.

The role of ATRX and ATRY in gonadal formation appears to be identical between mice and tammar, indicating a highly conserved and fundamental role in gonadal development in mammals. We have previously shown that the marsupial specific Y-linked orthologue, $A T R Y$, is exclusively expressed in the developing marsupial testis [6]. In mice, ATRX was present in the somatic and germ cells of the bipotential gonad of both XX and $X Y$ fetuses before sexual differentiation. Similarly, in marsupials, ATRX was present in the somatic and germ cells of the bipotential XX gonad and ATRY in the bipotential XY gonad prior to sexual differentiation.
Despite their early expression, ATRX/Y does not appear to have a functional role in early gonadal formation since even the most severely affected ATR-X patients show signatures of normal early testis development. This is demonstrated by the absence of Müllerian ducts in ATR-X patients, confirming early testicular differentiation and the formation of functional Sertoli cells that secreted AMH [6].

After sexual differentiation and the initiation of testicular development, ATRX (in mice) and ATRY (in marsupials) became strongly nuclear and localized in the Sertoli and germ cells. This was consistent with in situ experiments showing mRNA localized in the forming seminiferous cords. The Sertoli cells are essential for maintaining testicular structure and function. Although ATRX may not be required for initial Sertoli cell development, the gonadal dysgenesis phenotypes seen in ATRX patients are consistent with deficient Sertoli cell maintenance. ATRX (in mice) and ATRY (in marsupials) also appears to have an important function in germ cell development as it is present in these cells in both mammals. However, testicular development and androgen secretion from the Leydig cells is still possible in germ cell deficient testes, suggesting that the lack of masculinization in ATR-X patients is not due to germ cell loss, but potentially a defect in the Leydig cells themselves. A recent study has shown the ATRX can enhance the expression of androgen-dependent genes through physical interaction with androgen receptor in a human Sertoli cell line [19]. In the absence of a definitive Leydig cell marker in the tammar wallaby testis, interstitial cells were classified on their location and morphology. Cells that morphologically resemble Leydig cells were ATRX positive (in mice) and ATRY positive (in marsupials) supporting the suggestion of a possible role in Leydig cell maintenance. However, we cannot exclude the possibility that the lack of androgen in ATR-X patients may be primarily caused by Sertoli cellmediated gonadal failure, but the expression profile raises the possibility of a more direct role for ATRX (in mice) and ATRY (in marsupials) in androgen function.

Although the marsupial specific Y-linked orthologue, $A T R Y$, is exclusively expressed in the developing marsupial testis [6], in the adult $A T R X$ and $A T R Y$ mRNA are co-expressed and the ATRX antibody does not discriminate between the two orthologues. Interestingly, in the adult testis, ATRX/Y was lost from the Sertoli cell lineage suggesting that while it appears to be initially required to maintain Sertoli cells and early testicular viability, it is not required for mature Sertoli cell function. However, ATRX/Y remained localized in the germ cell derivatives and was primarily detected in the type A spermatogonia located at the basement membrane of the seminiferous tubules. Thus there may be a direct 
role of ATRX/Y in maintaining spermatogonial stem cells. Taken together, the complex expression of ATRX and ATRY in the developing and adult testis suggests it functions in multiple cell lineages in both the somatic and germ cell compartments.

Since it is a rare $\mathrm{X}$-linked recessive condition, no female ATR-X patients have been identified to date, so a role for this gene in ovarian development has not been established. Our mRNA and protein localization analyses show that there is a highly conserved pattern of expression in the developing mammalian ovary. Initially, ATRX protein was cytoplasmic and nuclear, and was localized in the germ cells of the developing ovary (similar to the pattern seen in the indifferent XY gonad). A few days later, ATRX protein was pronounced and strictly nuclear in the germ cells that were congregated in nests. This was confirmed by whole mount in situ hybridization, showing punctate mRNA staining in the cortex of both the mouse and tammar ovaries, indicative of germ cell expression. There was no ATRX expression in the ovarian supporting cell lineage until puberty. ATRX was strongly nuclear in the granulosa cells of growing and atretic follicles. Interestingly, ATRX was absent in the flattened granulosa cells surrounding primordial follicles, but rapidly accumulated once the cells became cuboidal and the follicle was recruited to the growing pool. This suggests a potential role for ATRX in regulating granulosa cell growth during folliculogenesis. In addition to the supporting cells, ATRX was also present in the oocytes at all stages of follicular development. This is consistent with a continued role in germ cell maintenance as seen in the adult testis.

ATRX was also detected in the luteal cells of corpus luteum and in the theca cells of large antral follicles suggesting a possible function in steroidogenesis. In addition, ATRX was strong and nuclear in the ovarian surface epithelium where it may have role in proliferation and repair functions after ovulation. Interestingly, over $85 \%$ of ovarian cancers are derived from the ovarian surface epithelium [20] and ATRX has been shown to be upregulated in ovarian cancer cell lines [18].

The observed pattern of expression for ATRX and ATRY in the gonads of mice and marsupials was strikingly similar to that of DMRT1 in mice, humans and the tammar [16,21,22]. DMRT1 represents the most ancient and conserved gene in the sex determination pathway with orthologues involved in sexual development in flies and worms. DMRT1 is expressed at all the same stages of development as ATRX in mice and ATRY in marsupials and is distributed in the Sertoli and germ cells of the developing mammalian testis. In the adult, it is similarly lost from Sertoli cells but is maintained in the type A spermatogonia [16,22]. In the developing ovary, DMRT1 is present in the germ cells and then later seen in the granulosa cells and germ cells of the adult ovary [16]. The gonadal phenotype of ATR-X and DMRT1 patients is strikingly overlapping, with initial Sertoli cell development followed by gonadal dysgenesis [16,23-25]. Dmrt1 regulates germ cell proliferation in a cell autonomous and dosage dependent manner in mice, and its loss results in an increased incidence of teratomas $[26,27]$. In addition Dmrt1 is required to maintain Sertoli cell proliferation and viability [27]. Furthermore, haploinsufficiency of both ATRX and DMRT1 is compatible with normal ovarian development $[5,21,25]$. The strikingly similar protein distribution of ARTX and DMRT1 and the overlapping gonadal phenotypes (outlined in Table 1) between ATR-X and distal chromosome 9p deletion (including DMRT1) patients suggests a potential interaction between these two genes in the sexual development pathway. Furthermore, ATRX, like $D M R T 1$, represents an ancient and ultra-conserved gene in the sex determination cascade. Thus, together ATRX and DMRT1 represent the most conserved somatic and germ cell factors in all animal species.

\section{Conclusion}

All sites of ATRX/Y expression and protein distribution were consistent with phenotypes observed in ATR-X patients and suggest important roles for this gene in development of the CNS, limbs, phallus and gonads in all mammals. ATRX/Y expression and protein distribution in the gonad suggests it may regulate somatic and germ cell function and gametogenesis in both testicular and ovarian development. The conserved mammalian ATRX/Y expression pattern strikingly overlaps with that of DMRT1 suggesting an ancient and conserved interplay between these two genes in the development of the gonad. Finally, the similarity between the expression of $A T R X$ and $A T R Y$ in mammals and the mutant $x n p-1$ phenotype in C.elegans indicates an ultra-conserved role for this gene in development and maintenance of the animal gonad $[15,16,28]$.

\section{Methods}

\section{Animals}

Tammar wallabies Macropus eugenii from Kangaroo Island (South Australia) were maintained in open grassy yards in our breeding colony in Melbourne, Australia. Pouch young were removed from their mother's pouch for analysis. When the day of birth was uncertain, age was estimated using head length and published growth curves [29]. Fetal samples were obtained from pregnant females after removal of the pouch young (designated as day 0 of gestation) as previously described [30,31]. Fetal mice were obtained from pregnant females with the day of vaginal plug designated as day 0.5 of gestation [32] All sampling techniques and collection of tissues 
conformed to Australian National Health and Medical Research Council guidelines (2004) and were approved by The University of Melbourne Animal Experimentation \& Ethics Committees.

\section{Tissues}

Three replicates were performed for each tissue or fetus for the immunohistochemistry and in situ hybridization. All tissues were collected under RNase-free conditions fixed overnight in $4 \%$ paraformaldehyde, washed several times in $1 \mathrm{X} \mathrm{PBS}$, and stored in $100 \%$ methanol at $-20^{\circ} \mathrm{C}$ before paraffin embedding and sectioning at $8 \mu \mathrm{m}$ for immunohistochemistry, or rehydrating in to PBS for in situ hybridization.

\section{mRNA in situ hybridization}

Whole-mount in situ hybridisation was carried out using standard methods [33] Antisense and sense RNA probes were prepared separately from a region of ATRX spanning exons 10-12 that is highly conserved between ATRX and ATRY using the following primers; Forward Primer: 5' CCTACTAAGCCTAAAGAGCAT 3'; Reverse Primer: 5' TCAAGGAGGAGGATTATTTTA $3^{\prime}$ and producing a product of $1113 \mathrm{bp}$. Probes were labeled with digoxigenin-UTP, incorporated by either SP6 or T7 RNA polymerase. Whole mount in situ hybridisation was carried out in groups according to stage and sex, with varying proteinase- $\mathrm{K}$ digestion times ranging from 270 seconds for gonads before sexual differentiation to 15 minutes for E16.5 mouse ovaries and post partum tammar wallaby ovaries. Testes were digested twice to enable probe penetration of the thick tunica. Whole embryos and gonads were hybridised with the $A T R X / Y$ in situ ribo-probe overnight at $65 \mathrm{C}$. The probe was detected with NBT/BCIP and photographs following dehydration and rehydration through a methanol series as described [32].

\section{Immunohistochemistry}

Antigen retrieval was performed in boiling $0.05 \mathrm{M}$ $\mathrm{NaCit}$ ( $\mathrm{pH} 7.0$ ) for 20 minutes. Sections were pre-treated with 3\% hydrogen peroxide in methanol for $15 \mathrm{~min}$ utes. The ATRX primary antibody (rabbit anti-human, Santa Cruz biotechnology, ATRX-H-300) was applied to tammar adult testis tissue sections at 1:150 dilutions at $4^{\circ} \mathrm{C}$ overnight. Signal was amplified using the ABC/HRP kit (DAKO) visualized with AEC+ chromogen (Thermo Scientific), and counterstained briefly with haematoxylin.

\section{Acknowledgements}

We thank all members of the wallaby research group and in particular Kerry Martin and Scott Brownlees for assistance with the animals. This study was supported by a National Health and Medical Research Council R D Wright Fellowship to AJP the Australian Research Council Centre of Excellence in
Kangaroo Genomics and a Federation Fellowship to MBR. There is no financial or other potential conflict of interest.

\section{Author details}

${ }^{1}$ ARC Centre of Excellence for Kangaroo Genomics, Australia. ${ }^{2}$ Department of Zoology, The University of Melbourne, Victoria, 3010, Australia. ${ }^{3}$ Research School of Biological Sciences, The Australian National University, ACT, 2601, Australia. ${ }^{4}$ Department of Molecular and Cellular Biology, The University of Connecticut, Storrs, CT 06269 USA.

\section{Authors' contributions}

All authors participated in the design of the study. Tissue samples were collected by MBR and AP. AP and KH performed all the experiments. Results were analyzed by AP and $\mathrm{KH}$ who also drafted the manuscript. All authors read, modified and approved the final manuscript.

Received: 20 January 2011 Accepted: 14 June 2011

Published: 14 June 2011

\section{References}

1. Picketts DJ, Higgs DR, Bachoo S, Blake DJ, Quarrell OW, Gibbons RJ: ATRX encodes a novel member of the SNF2 family of proteins: mutations point to a common mechanism underlying the ATR-X syndrome. Hum Mol Genet 1996, 5:1899-907.

2. Gibbons R: Alpha thalassaemia-mental retardation, linked. Orphanet J Rare Dis 2006, 1:15.

3. Gibbons RJ, Brueton L, Buckle VJ, Burn J, Clayton-Smith J, Davison BC, Gardner RJ, Homfray T, Kearney L, Kingston HM, et al: Clinical and hematologic aspects of the X-linked alpha-thalassemia/mental retardation syndrome (ATR-X). Am J Med Genet 1995, 55:288-99.

4. Ion A, Telvi L, Chaussain JL, Galacteros F, Valayer J, Fellous M, McElreavey K: A novel mutation in the putative DNA helicase $\mathrm{XH} 2$ is responsible for male-to-female sex reversal associated with an atypical form of the ATRX syndrome. Am J Hum Genet 1996, 58:1185-91.

5. Gibbons RJ, Higgs DR: Molecular-clinical spectrum of the ATR-X syndrome. Am J Med Genet 2000, 97:204-12.

6. Pask A, Renfree MB, Marshall Graves JA: The human sex-reversing ATRX gene has a homologue on the marsupial Y chromosome, ATRY: implications for the evolution of mammalian sex determination. Proc Natl Acad Sci USA 2000, 97:13198-202.

7. McPherson EW, Clemens MM, Gibbons RJ, Higgs DR: X-linked alphathalassemia/mental retardation (ATR-X) syndrome: a new kindred with severe genital anomalies and mild hematologic expression. Am J Med Genet 1995, 55:302-6.

8. Wilkie AO, Pembrey ME, Gibbons RJ, Higgs DR, Porteous ME, Burn J, Winter RM: The non-deletion type of alpha thalassaemia/mental retardation: a recognisable dysmorphic syndrome with X linked inheritance. J Med Genet 1991, 28:724.

9. Wilkie $A O$, Zeitlin HC, Lindenbaum RH, Buckle VJ, Fischel-Ghodsian N, Chui DH, Gardner-Medwin D, MacGillivray MH, Weatherall DJ, Higgs DR: Clinical features and molecular analysis of the alpha thalassemia/mental retardation syndromes. II. Cases without detectable abnormality of the alpha globin complex. Am J Hum Genet 1990, 46:1127-40.

10. Gibbons RJ, Higgs DR: The alpha-thalassemia/mental retardation syndromes. Medicine (Baltimore) 1996, 75:45-52.

11. Picketts DJ, Tastan AO, Higgs DR, Gibbons RJ: Comparison of the human and murine ATRX gene identifies highly conserved, functionally important domains. Mamm Genome 1998, 9:400-3.

12. Park DJ, Pask AJ, Huynh K, Renfree MB, Harley VR, Graves JA: Comparative analysis of ATRX, a chromatin remodeling protein. Gene 2004, 339:39-48.

13. Park DJ, Pask AJ, Huynh K, Harley VR, Renfree MB, Graves JA: Characterisation of the marsupial-specific ATRY gene: implications for the evolution of male-specific function. Gene 2005, 362:29-36.

14. Tang P, Argentaro A, Pask AJ, O'Donnell L, Marshall-Graves J, Familari M, Harley VR: Localisation of the Chromatin Remodelling Protein, ATRX in the Adult Testis. J Reprod Dev 2009.

15. Bender AM, Wells O, Fay DS: lin-35/Rb and xnp-1/ATR-X function redundantly to control somatic gonad development in C. elegans. Dev Biol 2004, 273:335-49.

16. Pask AJ, Behringer RR, Renfree MB: Expression of DMRT1 in the mammalian ovary and testis-from marsupials to mice. Cytogenet Genome Res 2003, 101:229-36. 
17. Haraguchi R, Suzuki K, Murakami R, Sakai M, Kamikawa M, Kengaku M, Sekine K, Kawano H, Kato S, Ueno N, et al: Molecular analysis of external genitalia formation: the role of fibroblast growth factor (Fgf) genes during genital tubercle formation. Development 2000, 127:2471-9.

18. Hrabovszky Z, Farmer PJ, Hutson JM: Undescended testis is accompanied by calcitonin gene related peptide accumulation within the sensory nucleus of the genitofemoral nerve in trans-scrotal rats. J Urol 2001, 165:1015-8.

19. Bagheri-Fam S, Argentaro A, Svingen T, Combes A, Sinclair A, Koopman P, Harley VR: Defective survival of proliferating Sertoli cells and androgen receptor function in a mouse model of the ATR-X syndrome. Hum Mol Genet 2011.

20. Auersperg N, Wong AS, Choi KC, Kang SK, Leung PC: Ovarian surface epithelium: biology, endocrinology, and pathology. Endocr Rev 2001, 22:255-88.

21. Raymond CS, Murphy MW, O'Sullivan MG, Bardwell VJ, Zarkower D: Dmrt1, a gene related to worm and fly sexual regulators, is required for mammalian testis differentiation. Genes Dev 2000, 14:2587-95.

22. Raymond CS, Kettlewell JR, Hirsch B, Bardwell VJ, Zarkower D: Expression of Dmrt1 in the genital ridge of mouse and chicken embryos suggests a role in vertebrate sexual development. Dev Biol 1999, 215:208-20.

23. Raymond CS, Parker ED, Kettlewell JR, Brown LG, Page DC, Kusz K, Jaruzelska J, Reinberg Y, Flejter WL, Bardwell VJ, et al: A region of human chromosome $9 p$ required for testis development contains two genes related to known sexual regulators. Hum Mol Genet 1999, 8:989-96.

24. Tang P, Park DJ, Marshall Graves JA, Harley VR: Trends Endocrinol Metab 2004, 15:339-44.

25. Villard L, Fontes M: Alpha-thalassemia/mental retardation syndrome, $\mathrm{X}$ Linked (ATR-X, MIM \#301040, ATR-X/XNP/XH2 gene MIM \#300032). Eur J Hum Genet 2002, 10:223-5.

26. Krentz AD, Murphy MW, Kim S, Cook MS, Capel B, Zhu R, Matin A, Sarver AL, Parker KL, Griswold MD, et al: The DM domain protein DMRT1 is a dose-sensitive regulator of fetal germ cell proliferation and pluripotency. Proc Natl Acad Sci USA 2009, 106:22323-8.

27. Kim S, Bardwell VJ, Zarkower D: Cell type-autonomous and nonautonomous requirements for Dmrt1 in postnatal testis differentiation. Dev Biol 2007, 307:314-27.

28. Steensma DP, Gibbons RJ, Mesa RA, Tefferi A, Higgs DR: Somatic point mutations in RUNX1/CBFA2/AML1 are common in high-risk myelodysplastic syndrome, but not in myelofibrosis with myeloid metaplasia. Eur J Haematol 2005, 74:47-53.

29. Poole WE, Simms NG, Wood JT, Lubulwa M: Tables for age determination of the Kangaroo Island wallaby (tammar), Macropus eugenii, from body measurements. CSIRO Division of Wildlife and Ecology 1991, Canberra.

30. Renfree MB: The composition of fetal fluids of the marsupial Macropus eugenii. Dev Biol 1973, 33:62-79.

31. Tyndale-Biscoe $\mathrm{CH}$, Renfree MB: Reproductive physiology of marsupials. Cambridge Cambridgeshire; New York: Cambridge University Press; 1987.

32. Nagy A: Manipulating the mouse embryo: a laboratory manual. Cold Spring Harbor, N.Y.: Cold Spring Harbor Laboratory Press; 32003.

33. Wilkinson DG: In situ hybridization: a practical approach. Oxford; New York: IRL Press at Oxford University Press; 1992.

\section{doi:10.1186/1471-213X-11-39}

Cite this article as: Huyhn et al:: ATRX has a critical and conserved role in mammalian sexual differentiation. BMC Developmental Biology 2011 11:39.

\section{Submit your next manuscript to BioMed Central and take full advantage of:}

- Convenient online submission

- Thorough peer review

- No space constraints or color figure charges

- Immediate publication on acceptance

- Inclusion in PubMed, CAS, Scopus and Google Scholar

- Research which is freely available for redistribution 